ISSN 1517-5901 (online)

POLÍTICA \& TRABALHO

Revista de Ciências Sociais, $n^{\circ}$ 47, Junho/Dezembro de 2017, p. 57-74

\title{
DENTRO E FORA DO OCTÓGONO: corpo, consumo e êxtase nas tramas do MMA
}

\section{INSIDE AND OUTSIDE OF THE OCTAGON: body, consumption and ecstasy in the plot of the MMA}

\author{
João Batista de Menezes Bittencourt* \\ Felipe Chaves Guimarães**
}

\begin{abstract}
Resumo
O presente artigo busca discutir o fenômeno social e esportivo conhecido como MMA (Mixed Martial Arts), a partir de uma reflexão sobre os usos dos corpos e as práticas de consumo dos espectadores e praticantes desse esporte na cidade de Maceió/AL. A pesquisa etnográfica foi realizada em três espaços distintos: um bar que reunia fãs e/ou adeptos do esporte, uma academia de musculação que oferecia treinos de MMA e um evento com lutadores profissionais chamado Coliseu Extreme Fight. Por intermédio da observação participante e entrevistas realizadas com espectadores e praticantes do MMA em Maceió, foi possível compreender os diferentes sentidos elaborados pelos consumidores desse esporteentretenimento.
\end{abstract}

Palavras-chave: Corpo. Consumo. Êxtase. MMA.

\begin{abstract}
This article aims to discuss the social and sportive phenomenon known as MMA (Mixed Martial Arts), from reflections on uses the bodies and consumption practices of spectators and practitioners of this sport in the city of Maceió / AL. The ethnographic research was realized in three distinct spaces: a bar that broughted together fans and / or sports adepts, a bodybuilding gym that offer MMA training and an event with professional fighters called the Extreme Fight Coliseum. Through participant observation and interviews with spectators and MMA practitioners in Maceió, it was possible to understand the different senses elaborated by the consumers of this sport-entertainment.
\end{abstract}

Keywords: Body. Consumption. Ecstasy. MMA.

\footnotetext{
* Professor dos Programas de Pós-Graduação em Sociologia e Antropologia Social da Universidade Federal de Alagoas/Brasil. Doutor em Ciências Sociais pela UNICAMP/Brasil. E-mail: joao.bittencourt@ ics.ufal.br

** Mestre em Sociologia pela Universidade Federal de Alagoas/Brasil. E-mail: felipe@felipeguimaraes. com.br
} 


\section{Introdução}

Fenômeno esportivo e midiático de projeção internacional, o MMA é um dos esportes que mais tem crescido - econômica e popularmente nos últimos anos. Capitaneado pela marca $\mathrm{UFC}^{1}$ - uma das mais valiosas do mundo esportivo ao lado da $\mathrm{NFL}^{2}$ e da $\mathrm{NBA}^{3}$-, o MMA conseguiu atingir números surpreendentes. A maior prova do seu crescimento vertiginoso reflete-se no fato de que atualmente o UFC é o maior provedor de eventos pay-per-view, transmitido via TV aberta, a cabo e por satélite para mais de 145 países no mundo todo (LANCEPRESS, 2013). Por ano, o faturamento do UFC só com combates fica em torno de U\$\$ 500 milhões.

Esses dados já contêm elementos suficientes para atestar a grandiosidade do fenômeno, porém, a nossa proposta no artigo é explorar as significações sociais e culturais que são mobilizadas pelo MMA. Desse modo, fizemos opção pelo estudo das práticas corporais e de consumo dos espectadores e iniciados nesse esporte. É a partir da leitura dos sentidos mobilizados por esses agentes que buscaremos algumas pistas para entender a popularização desse esporte que no Brasil vem batendo recordes de audiência. ${ }^{4}$

Nossa pesquisa foi realizada na cidade de Maceió, onde tivemos a oportunidade de acompanhar os agentes em diferentes espaços e situações. Os locais escolhidos foram: o Bar Red \& Blue localizado no bairro Jatiúca; a academia Donosti localizada no bairro Barro Duro; o evento Coliseu Extreme Fight que aconteceu em setembro de 2013 em uma famosa casa de shows da região. Essas incursões permitiram que tivéssemos acesso às experiências vivenciadas pelos praticantes e espectadores, pois, apesar de ambos terem em comum o gosto pelo esporte, não podemos perder de vista os aspectos que dizem respeito aos usos dos corpos em distintos contextos.

Antes de adentrarmos nos pormenores da pesquisa empírica, apresentaremos alguns elementos teórico-metodológicos que orientaram nossas reflexões, situandoas na tradição de uma socioantropologia do corpo.

Primeiramente é importante destacar que os estudos sociológicos e antropológicos sobre o corpo são bastante recentes e datam da segunda metade do século XX. Apesar de alguns textos clássicos terem sido produzidos na primeira metade, como por exemplo, "A preeminência da mão direita” de Robert Hertz (1980)

\footnotetext{
1 Ultimate Fighting Championship.

2 National Footbal League.

3 National Basketball Association.

4 Guimarães (2014) indica que o número de assinantes pay-per-view do "Canal Combate", especializado em artes marciais e oferecido pela Globosat para a televisão fechada, reflete o interesse do público brasileiro pelas lutas. Em 2006, o canal possuía 13 mil assinantes. O número aumentou para $87 \mathrm{mil} \mathrm{em}$ 2010, atingiu os $130 \mathrm{mil}$ assinantes em 2011, passou para $240 \mathrm{mil} \mathrm{em} 2012$ e fechou o ano de 2013 com 360 mil assinantes.
} 
- originalmente publicado em 1909, “A noção de técnica do corpo” de Marcel Mauss (2003), de 1936, ou ainda o Processo Civilizador de Norbert Elias (1990), cujo ano de publicação é 1939, não existia dentro do pensamento social uma vertente exclusiva de estudos que se debruçasse sobre as experiências e práticas corporais. O antropólogo David Le Breton (2011) indica que uma Sociologia do Corpo só foi possível quando este passou a figurar no conjunto das preocupações sociais vigentes, e segundo o autor, isso só aconteceu no final dos anos 1960, influenciado pela luta feminista, pela revolução sexual, o desenvolvimento da expressão corporal, a emergência de novas terapias etc.

O corpo, lugar do contato privilegiado com o mundo, está sob a luz dos holofotes. Problemática coerente e até inevitável numa sociedade de tipo individualista que entra em uma zona turbulenta, de confusão e de obscurecimento das referências incontestáveis e conhece, em consequência, um retorno maior a individualidade (LE BRETON, 2011, p. 10).

Desse modo, assistimos no final dos anos 1960, a "entrada triunfal do corpo nas ciências sociais" (LE BRETON, 2011) a partir de abordagens que priorizavam aspectos que podemos definir como mais "individuais", pois se debruçavam sobre as experiências dos agentes produzidas no e pelo corpo. Autores como Jean Baudrillard, Pierre Bourdieu, Norbert Elias, Michel Foucault e Erving Goffman são alguns importantes representantes dessa vertente de pensamento que começava a ganhar forma nesse período. É importante destacar que não houve a institucionalização de uma disciplina ou de uma área do conhecimento, mas sim, o aparecimento de pesquisas que passaram a se preocupar de maneira mais incisiva pelas práticas corporais, o que possui relação com o desenvolvimento de perspectivas teóricas que tendem a priorizar as trajetórias individuais, os processos de subjetivação bem como os processos de formação do self.

O aparecimento na década de 1980 de abordagens nas Ciências Sociais que traziam em seu arcabouço conceitual ideias como "agência", "prática" e "reflexividade" inaugurou um novo momento da Sociologia e Antropologia do Corpo. Se já havia uma preocupação com as experiências incorporadas dos agentes, estas passaram a ser imprescindíveis para uma leitura mais robusta da realidade social. Essas abordagens, que têm entre seus principais representantes nomes como Pierre Bourdieu (1972), Anthony Giddens (1984), Marshall Sahlins (1987) e Sherry Ortner (1984) despontam como possibilidades de ruptura com o binarismo que por muito tempo organizou o pensamento social em pares de opostos, tais como: "estrutura x sujeito", “indivíduo x sociedade" ou "estrutura x agência”. Para esses autores, não existem dimensões essencializadas, seja numa perspectiva macro ou micro, e sim interação e complementaridade. Os agentes ocupam posições sociais que se situam dentro de uma estrutura organizada hierarquicamente, porém, eles atuam de maneira ativa e reflexiva, valendo-se de um repertório de significados que eles utilizam quando confrontados com situações cotidianas diversas. O corpo, por sua vez, é o espaço privilegiado de intersecção entre o dentro e o fora; entre o interior e o exterior. É através dele que os dispositivos de poder (FOUCAULT, 1988) 
subjetivizam, normalizam e docilizam as práticas e o pensamento, levando a uma exacerbada padronização das condutas, mas também é por ele que a resistência a esses dispositivos se expressa. É impossível discutir o problema da agência sem levar em consideração o corpo, não apenas por este servir de ponte para a dialética carne/ mundo, mas também por ser o espaço onde os agentes performatizam o que Sherry Ortner (2006) chama de "jogos sérios".

Dito isso, esclarecemos que a perspectiva teórica para a leitura das práticas corporais assumida nesse trabalho situa-se em uma zona intermediária entre estrutura e agência, pois, enfatiza tanto o impacto dos elementos estruturais na formação das subjetividades como também destaca a agência, situando-a enquanto condição decisiva da expressão humana em sociedade.

\section{Do lado de dentro - as experiências mobilizadas pelos praticantes do MMA}

Em um contexto de espetacularização promovido pelos meios de comunicação de massa, os corpos dos lutadores de MMA e os signos que eles exibem, passam a ser importantes referências para aqueles que buscam a prática do esporte, com o objetivo da profissionalização, ou mesmo visando apenas condicionamento físico. Uma das questões que tentamos responder em nossa pesquisa foi: "Quais os interesses mobilizados por aqueles que procuram praticar o MMA?". Nossa hipótese se relacionava à crescente influência que o esporte vinha exercendo sobre os jovens ${ }^{6}$ nas diferentes partes do país. Porém, havia outras questões que precisavam ser ponderadas para não corrermos o risco de considerar um único elemento como responsável pela produção das escolhas dos agentes.

Ao longo das idas a campo, dois conceitos foram fundamentais para problematizar a fabricação dos corpos e os sentidos elaborados pelos praticantes do MMA. São eles: técnica do corpo (MAUSS, 2003) e capital corporal (WACQUANT, 2002). O primeiro foi elaborado no ano de 1936 por Marcel Mauss, em um texto que versava sobre as diferenças no que diz respeito aos usos dos corpos nas sociedades ditas "tradicionais" e "modernas". As distintas formas dos homens e mulheres servirem-se dos seus corpos foram apresentadas através de inúmeros exemplos etnográficos sobre a prática do nado, da corrida, da marcha, do caminhar etc. Mauss pretendia com essa discussão mostrar que esses movimentos não são universais, eles fazem parte de um aprendizado, da incorporação de hábitos que "variam sobretudo com as sociedades, as educações, as conveniências e as modas, os prestígios” (MAUSS, 2003, p. 404).

\footnotetext{
5 Para a antropóloga, a vida social é organizada a partir dos “jogos sérios”, ou jogos que os agentes consideram que valem a pena ser jogados. Estes, por sua vez, compreendem metas e/ou projetos que são produzidos culturalmente e envolvem práticas de rotina e ações intencionais.

6 É importante esclarecer que a categoria jovem não assume uma dimensão analítica em nosso trabalho, ou seja, não se busca compreender os sentidos investidos pelos indivíduos a partir de sua condição juvenil. Apesar de entendermos que se trata de um importante marcador social, escolhemos utilizar a categoria jovem por esta abarcar a faixa etária de nossos interlocutores, que varia entre 18 a 29 anos.
} 
Já a noção de capital corporal compreende uma espécie de recurso que os pugilistas dispõem para garantir sucesso na profissão. Em sua famosa etnografia de um clube de boxe localizado em um bairro do gueto negro de Chicago, o antropólogo francês apresenta os corpos dos lutadores de boxe como máquinas que precisam ser bem cuidadas, afirmação extraída das falas dos próprios pugilistas. Wacquant sugere que o boxe, mais do que qualquer outro esporte, requer, uma gestão meticulosa do corpo que se expressa dentro e fora dos ringues. Nesse sentido, o corpo do lutador do MMA guarda muitas semelhanças com o do lutador de boxe, ele também precisa ser administrado de maneira adequada para aguentar a intensidade dos combates e, claro, precisa estar bem preparado, porque é um corpo que precisa corresponder ao alto investimento financeiro de empresários que faturam quantias exorbitantes com o mercado do MMA. Certamente, existem diferenças enormes entre a fabricação dos corpos de atletas profissionais e amadores, porém, a ideia de "gestão corporal" se faz presente em ambos os casos. Como poderemos observar a seguir.

A academia escolhida para o acompanhamento dos praticantes foi o Centro de Treinamentos Donosti, localizada no Bairro Barro Duro. Instalado em um amplo galpão à beira de uma movimentada avenida da cidade, oferece aulas diárias de jiujitsu e aulas de MMA duas vezes por semana, além de outras modalidades como muay thai, karatê, boxe e krav maga, ${ }^{7}$ além de musculação e pilates.

Figura 1 - Vista interna da Academia Donosti

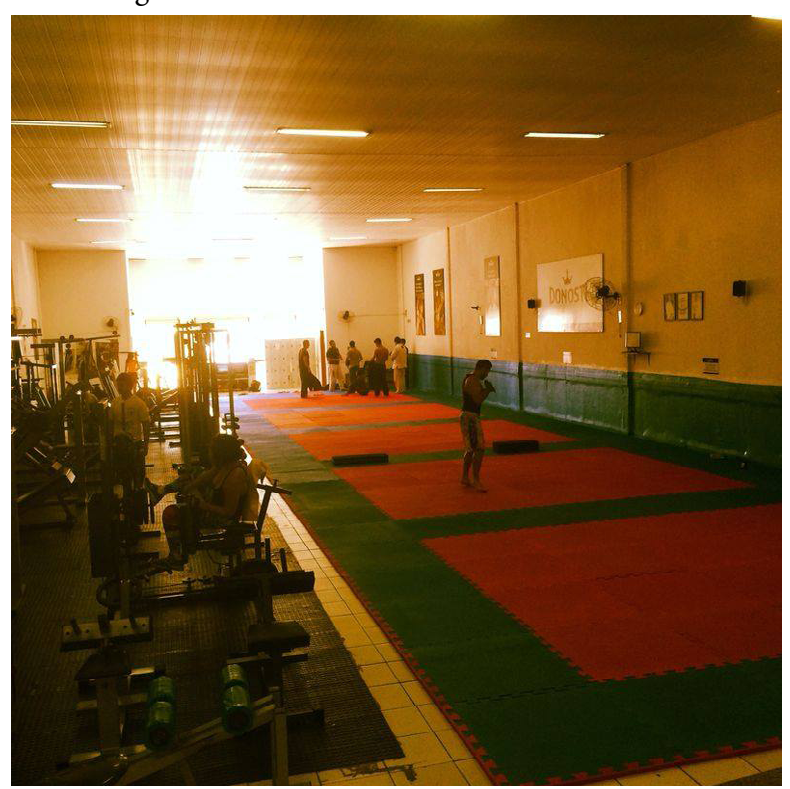

Fonte: https://www.facebook.com/pg/Donostict/photos/?ref=page_internal.

Acesso em: março de 2013.

7 Jiu-jitsu, muay thai, karatê, boxe e krav maga são modalidades básicas para o MMA. 
São muitas as motivações que envolvem a procura pela prática das diversas modalidades de artes marciais nas academias. Entretanto, desde 2008, a demanda pelo jiu-jítsu, muay thai e MMA tem crescido consideravelmente em Maceió. Para Rodrigo, 32 anos, proprietário da academia Donosti, o crescente interesse pelas modalidades que formam a base do MMA, e até mesmo o interesse pela prática do próprio MMA, reflete a popularização do UFC no Brasil:

O jiu-jítsu teve seu boom ao longo das décadas de 1980 e 1990. Naquela época, tal modalidade era encarada como a arte marcial mais eficaz durante os combates. Com a popularização do jiu-jítsu, os lutadores tiveram de incluir em sua performance golpes de outras modalidades. Atualmente, o lutador mais completo é aquele que domina as técnicas de várias artes marciais (Entrevista realizada em.20/12/2012).

Dessa forma, o sentido de artes marciais mistas ganhou ainda mais relevância, chegando a ser formatado como uma modalidade que pode ser ensinada àqueles que desejarem. Observando pela ótica conceitual, ofertar aulas de MMA não teria sentido, uma vez que o MMA é a junção de várias modalidades e pressupõe certo domínio de cada arte marcial. No entanto, o que identificamos ao observar as diversas aulas de MMA é que as academias criaram um produto para ser consumido por aqueles que desejam praticar as artes marciais mistas na condição de atividade esportiva e não na condição de arte marcial tradicional.

Aspectos como a falta de um ritual específico de saudação, a não obrigatoriedade do uso de uma vestimenta característica para a prática da aula (como o quimono), a inexistência de uma hierarquia disciplinar para com o mestre e a falta de cobrança de movimentos simétricos e precisos fazem do MMA um esporte híbrido. Nesse sentido, definitivamente, não podemos encarar o MMA como uma arte marcial. Com esse novo produto, o que importa é a atividade física em seu sentido mais abrangente, ou seja, de condicionamento das valências físicas e motoras. Nos tatames das academias que ofertam o MMA, o que importa é o corpo; este é tratado como o objeto a ser delineado.

A busca pela saúde e pela beleza, por meio da prática da atividade física, favorece tanto o foco no emagrecimento como o foco na definição dos músculos. $\mathrm{O}$ corpo belo, tonificado e milimetricamente definido torna-se um projeto pessoal para muitos homens e mulheres que lotam as academias. Aliado ao discurso da busca pelo corpo ideal, há também aquele que patologiza a obesidade, definindo-a como uma doença que precisa ser combatida.

Vivemos em um contexto sócio-histórico em que o corpo e o self se encontram entrelaçados. A divisão entre exterioridade e interioridade foi borrada e estamos assistindo a um processo de somatização dos movimentos de subjetivação que pode ser expressa pela frase "meu corpo sou eu". Ortega e Zorzanelli (2010) sugerem que cada vez mais estamos definindo nossa subjetividade em termos corporais e biomédicos. 
No horizonte desse processo, a otimização dos padrões corporais tornou-se um parâmetro de medida e de valor para o homem dito pós-moderno. Criamse modelos ideais de sujeitos baseados na performance física e se estabelecem novos parâmetros de mérito e reconhecimento cujas bases são as regras higiênicas. As ações individuais passam a ser dirigidas com o objetivo de obter melhor forma física, mais longevidade ou prolongamento da juventude (ORTEGA; ZORZANELLI, 2010, p. 75).

Os aparentes resultados de emagrecimento e tonificação do corpo têm motivado indivíduos a se matricular nas aulas de MMA e também em outras modalidades, como o muay thai. Pessoas que nunca antes tiveram relação com uma arte marcial, ou mesmo com qualquer tipo de luta, matriculam-se nas academias buscando a fabricação de um corpo que se adeque aos padrões estéticos emergentes. Em uma das entrevistas realizadas na academia Donosti, uma praticante de 26 anos fala sobre o que a motivou a escolher o MMA como esporte:

Quando eu comecei, eu comecei pelo físico. Eu vim ver uma aula primeiro e como eu sou da área de saúde - eu sou fisioterapeuta - eu vi que trabalhava bastante o corpo. Eu comecei por isso. Mas depois que eu comecei a fazer eu comecei a me interessar também por esta parte da luta em si (Entrevista realizada em: 20/11/2012).

Com discurso semelhante, um outro aluno de 20 anos, explica como foi seu processo de incursão na prática do MMA e posteriormente do muay thai:

Eu precisava emagrecer 15 quilos. Aí eu comecei fazendo MMA porque eu sempre me interessei por lutas. O judô e o caratê eu já tinha feito na época de escola, quando eu tinha 12 anos. Mas eu queria uma coisa mais moderna. Aí eu vim fazer uma aula experimental de MMA e gostei. Eu já via na TV e gostei quando testei a aula na prática. Eu fiz MMA uns dois meses, mas vi que eu gostava mesmo era mais da trocação ${ }^{8}$ do que da parte do chão, que é a parte do jiu-jitsu. Aí eu saí do MMA e fui fazer o muay thai. Sabe o Anderson Silva, né? Ele é mestre de muay thai, por isso ele dá aqueles chutes, tá ligado? Eu vou ficar um tempo no muay thai pra aprender melhor. Depois eu volto pro MMA pra melhorar o meu chão (Entrevista realizada em: 20/11/2012).

Para o nosso entrevistado, o MMA foi a porta de entrada para uma tentativa de praticar uma luta mais "atual", mais "moderna". Após treinar por cerca de 2 meses, o aluno decidiu migrar para o muay thai por entender que precisava desenvolver seus golpes, especializando-se primeiramente numa arte marcial única. Esse processo migratório é comum para os praticantes do MMA.

8 A "trocação" é o momento da luta em que os oponentes concentram os golpes em chutes e socos em pé. No mundo da luta, essa ação ficou conhecida como "trocar chutes e socos". 
Além do interesse na luta, ele também buscava uma atividade física que o ajudasse a perder peso. Realmente podemos notar que o processo de espetacularização que envolve as artes marciais mistas tem cumprido o objetivo de vender alguns valores simbólicos para seu público-alvo, que prontamente responde a tais ofertas com seus comportamentos de compra.

O sistema simbólico do UFC vende essa noção de saúde e beleza corporal. A lógica do culto ao corpo é notada de imediato ao analisarmos os lutadores. Do "pesomosca" ao "peso-pesado", o condicionamento físico dos atletas é expresso por meio do corpo. Tal qual mais um recurso de comprovação da eficiência desse esporte, a supremacia muscular fica evidente independentemente da categoria em que o atleta se enquadra.

Durante os eventos de pesagem ${ }^{9}$, em meio às provocações entre os atletas, os lutadores costumam tirar suas camisas para exibir sua musculatura tonificada como símbolo de força e supremacia físico-técnica. Sabemos, pois, que a utilização do corpo como uma vitrine repleta de significações estéticas insere-se no contexto das mais diversas modalidades de luta esportiva há tempos, e o MMA não foge a essa regra.

Em seu trabalho etnográfico junto aos lutadores de boxe, Wacquant (1998) pôde perceber o cuidado e também a idolatria daqueles homens para com o seu corpo, que é encarado tanto como um sistema de propagação da força do lutador quanto como sua ferramenta de trabalho propriamente dita:

Na cultura pugilística, não é o rosto que cicatriza o sentimento de identidade [...], mas sim o organismo inteiro e especialmente o torso, sede do "coração", que no jargão profissional designa a mais reverenciada qualidade do autêntico lutador [...]. Exibir um físico firme, rijo, belicoso no ringue torna-se uma questão de intenso orgulho, tanto pessoal quanto profissional. [...]. A associação íntima entre porte corporal e trabalho corporal é uma outra maneira de comunicar a fusão da estética e da pragmática do pugilismo. O outro lado da moeda da eficiência resplandecente é a implacável obrigação de cuidados com o corpo e a angústia aguda relativa à decadência e ao abandono. Boxeadores, técnicos e treinadores trabalham em íntima colaboração para preservar e proteger o capital corporal do lutador, pelo treinamento consciencioso, a vida virtuosa e a seleção e o escalonamento adequados das lutas. "Cuido do meu corpo como se estivesse cuidando de meu próprio filho", declara um meio-médio negro de 20 anos [...] (WACQUANT, 1998, p. 81 - grifos do autor).

Estamos diante de uma adesão cada vez maior por parte dos indivíduos do incremento da lógica de um capital corporal (WACQUANT, 2002). Numa sociedade em que cada vez mais o corpo é celebrado, seja por meio da prática de exercícios físicos, passando pelo controle da alimentação como meio para se chegar à beleza desejada, seja

9 A pesagem é um evento em que os oponentes se encontram para conferir se estão dentro da faixa de peso requisitada pela sua categoria. Tais eventos representam também um aquecimento mercadológico para a luta, sendo exibidos nos canais de luta e repercutidos nos veículos de comunicação e redes sociais. 
por meio da realização de procedimentos estéticos em clínicas especializadas, o corpovitrine dos atletas profissionais abarca o sentido de sucesso desejado.

Ao problematizar aspectos relacionados à formação da autoidentidade no contexto contemporâneo, Anthony Giddens (2002, p. 76) indica que a "reflexividade do eu se estende ao corpo, onde o corpo é parte de um sistema de ação em vez de um mero objeto passivo". Apoiados na perspectiva desenvolvida pelo sociólogo inglês, podemos dizer que as escolhas dos entrevistados pela prática esportiva visando à perda de peso ou o embelezamento corporal, fazem parte desse programa de monitoramento reflexivo realizado pelo agente. Essa argumentação confronta a ideia de que os corpos são construtos passivos agenciados por dispositivos de poder, seja o discurso médico, seja o discurso midiático. Entendemos que uma perspectiva não exclui a outra, uma vez que não podemos descartar nem a influência dos fluxos de saber-poder (FOUCAULT, 2009) sobre os corpos, nem o fato de que atualmente mudanças na balança nós-eu (ELIAS, 1994) produziram indivíduos mais reflexivos.

\section{Do lado de fora - as experiências mobilizadas pelos espectadores do MMA}

Juntamente com o aumento das academias de musculação que oferecem aulas de MMA, nos deparamos com outro fenômeno: a expansão de redes de sociabilidades construídas em torno do esporte. Seja em bares, em residências particulares ou em eventos que oferecem ao público lutas com atletas profissionais, encontramos pessoas que vibram excessivamente quando um lutador nocauteia seu oponente, levando-o à lona. Corpos excitados que encontraram nessa prática esportiva uma forma de lazer e diversão semelhante aos já conhecidos encontros de torcedores para acompanhar partidas de futebol.

Em Maceió, é grande o número de bares que optam por transmitir as lutas em dia de combates que envolvem brasileiros. Na Avenida Dr. Antônio Gomes de Barros, localizada numa área valorizada da cidade, quase a totalidade dos bares exibiram a luta entre Anderson Silva e Chris Weidman ${ }^{10}$ ocorrida no final de dezembro de 2013. Outras pessoas, entretanto, preferem se reunir em casas de amigos para desfrutar das lutas de forma mais à vontade e mais barata.

Naquele sábado, 28 de dezembro de 2013, no bar Red \& Blue da Avenida Amélia Rosa em Maceió/AL, os aparelhos de televisão transmitiriam a luta a um público expressivo de clientes, comprovando a popularidade do MMA. A euforia tomava conta dos espectadores que naquela noite resolveram chegar horas antes do

\footnotetext{
10 Essa luta foi considerada uma tentativa de revanche para o brasileiro Anderson Silva, uma vez que ele havia sido derrotado por Chris Weidman no dia 6 de julho de 2013. A possibilidade de uma boa atuação do lutador brasileiro fez com que o evento ganhasse repercussão mundial, sendo considerada por muitos como "A revanche do século". Porém, no segundo round, Anderson Silva sofreu uma grave fratura na perna esquerda, perdendo a luta e o título que estava em disputa. Ver: http://sportv.globo.com/site/ combate/noticia/2013/12/anderson-silva-sofre-fratura-exposta-em-chute-e-weidman-mantem-o-titulo. html.
} 
evento mais esperado com o intuito de garantir um local privilegiado próximo aos televisores do bar.

Na mesa 21, Marcelo, 25 anos, alternava seu foco entre os golpes do combate e um gole de cerveja. Com mais cinco colegas - todos do sexo masculino - o estudante de administração assistia à luta da mesma forma como vem fazendo há cerca de três anos.

Há certo tempo os bares começaram a atentar para esse movimento. Nos dias de luta do UFC, é comum ver esses locais cheios, sobretudo quando há participação de um atleta brasileiro em algum confronto. Nas ocasiões em que existe uma disputa de cinturão, a concorrência para ocupar uma mesa com boa visibilidade para os telões e televisores é ainda maior.

Assistir aos combates do UFC em bares pela madrugada virou opção de lazer tanto para os que acompanham o esporte com certa periodicidade como para aquelas pessoas que não possuem intimidade suficiente com as lutas. Num comportamento muito parecido com o das reuniões entre amigos para assistir aos jogos de futebol, o fato é que indivíduos das mais variadas idades e classes sociais passaram a incluir as lutas de MMA em suas programações de lazer no fim de semana.

Em Maceió, nas noites de combate em que há disputa por cinturão, até mesmo casas de shows planejam suas atrações levando em consideração que vão perder boa parte de seu público para os bares que transmitem as lutas.

Do momento em que chegam até o horário de ir embora, os clientes consomem uma quantidade considerável de bebidas alcoólicas - basicamente cerveja - e variados tipos de entradas, ou "tira-gostos". Para Maxwell, garçom do bar Red \& Blue, nas noites de lutas do UFC, as vendas da casa aumentam consideravelmente: "Toda vez que tem luta do vale-tudo a casa fica cheia. Parece jogo de futebol no dia de domingo, só que é de noite e de madrugada. Quando tem um brasileiro forte para lutar, aí é que o negócio fica bom porque todo mundo quer ver" (Entrevista realizada em: 28/12/2013).

Esse comportamento se repete em várias cidades do Brasil. As lutas que envolvem os brasileiros campeões de suas categorias mobilizam milhares de pessoas em frente aos televisores de suas casas ou bares. Proprietários de bares e casas noturnas já identificaram o tamanho desse mercado e vêm investindo na compra de monitores televisivos, projetores e sistemas de áudio.

Ficar no bar por cerca de 5 horas, entre $21 \mathrm{~h}$ e $2 \mathrm{~h}$, para assistir a todas as lutas do UFC tornou-se um hábito entre vários grupos de amigos. Os combates são a "saída da noite" para muitos daqueles que não querem ir a uma boate, como nos mostra Diego (23 anos):

A gente gosta de assistir o UFC no barzinho porque você já tem toda uma estrutura já pronta. E vem muita gente conhecida também. Hoje assistir o UFC é a saída da noite. Pra tu ver, tem mais gente que conheço que tá vindo assistir a luta do que tá indo pro Maikai [uma casa de shows em Maceió]. Hoje no Maikai só vai dar gente depois das 3 da manhã e olhe lá. [...] Eu gosto daqui porque você consegue ficar numa posição boa pra ver a luta e aqui a cerveja é gelada (Entrevista realizada em: 28/12/2013 - grifos nossos). 
A combinação de cerveja com as lutas do UFC representa uma relação de euforia mediada pelo consumo do entretenimento entre amigos na mesa do bar. Aquele momento de consumo da luta, do ato de assistir ao combate, transforma-se no consumo do entretenimento no sentido do viver o espetáculo e tudo o mais que ele venha a proporcionar.

Nesse instante, a noção de arte marcial mista como esporte é deixada de lado para dar espaço a um complexo sistema de oferta de valores por meio de sistemas simbólicos que são inerentes à força dos confrontos entre os lutadores. A atividade atlética passa, então, para a condição de esporte-entretenimento amparado pela magia do espetáculo.

Esse misto construído a partir do momento em que o espetáculo do MMA passou a ser encarado como esporte, de modo a utilizar as práticas e as regras sociais da atividade esportiva, representa a produção social de uma estrutura simbólica do êxtase dos combates. É esse o ponto de diferenciação das atuais lutas do UFC em relação aos antigos campeonatos de lutas livres combinadas. Os torneios atuais de MMA possuem um elevado grau de realidade porque, de fato, são reais na medida em que dois oponentes se digladiam até alguém desistir ou ser finalizado ao longo de 3 ou 5 rounds.

O público consumidor do UFC, em casa ou nos bares, espera justamente que seu lutador favorito finalize o oponente com um golpe certeiro. Quando isso ocorre, podemos dizer que o ápice da luta foi atingido. Para Thiago, 23 anos, estudante de jornalismo, todos estão ali esperando que um golpe seja encaixado:

A melhor parte da luta é a quando o lutador acerta o adversário com um golpe que pega em cheio. Aí o adversário cai e o outro lutador sobe em cima dele e começar a descer o cacete até o juiz pedir pra ele parar. Quando o juiz pede pra o outro parar, a luta acaba. Também é bom quando um lutador encaixa um golpe de jiu-jitsu - uma chave de braço, um enforcamento, uma chave de perna. Aí o adversário é obrigado a desistir, senão ele pode se machucar feio e até quebrar um braço ou uma perna (Entrevista realizada em: 28/12/2013).

Norbert Elias e Eric Dunning (1992) argumentam que a busca da excitaçãojogo se tornou uma marca das nossas sociedades, uma vez que as chamadas excitações sérias, que punham em risco a vida dos indivíduos diminuíram consideravelmente. A busca pelo prazer, pelo gozo irrefletido, acompanha a história da humanidade, porém, ela foi sofrendo mudanças ao longo do tempo em virtude de uma autorregulação individual dos impulsos mediante aprendizado.

Numa sociedade em que as inclinações para as excitações sérias e do tipo ameaçador diminuíram, a função compensadora da excitação jogo aumentou. Com o auxilio desse tipo de excitação, a esfera mimética oferece uma vez mais a oportunidade, por assim dizer, de um novo "desanuviar" no seio da sociedade que, pelo contrário, na vida social comum possui um conteúdo uniforme. (ELIAS; DUNING, 1992, p. 113). 
A categoria de esporte-entretenimento passa a ser criada na condição de principal mercadoria de um sistema de oferta do êxtase, cuja dimensão do espetáculo respeita os limites daquilo que é aceito como civilizado. As sensações trabalhadas por tal espetacularização são projetadas para um público que consome o desferimento dos golpes por entender que se trata de um conflito controlado.

A espetacularização do lazer por meio da atividade esportiva - ou mesmo a esportivização do lazer - inerente à estrutura simbólica dos combates de UFC, propicia a livre sensação de excitação que segundo Norbert Elias e Eric Duning, vem sendo tolhida dos indivíduos na sociedade contemporânea. O grito deflagrado, a contração dos músculos e a elevação da adrenalina de um espectador do MMA ao ver o encaixe perfeito de um soco no rosto do outro lutador representa a consolidação do êxtase frente ao enquadramento social imposto pelas regras de conduta. Ortega e Zorzanelli indicam que a fruição sensorial também se tornou um imperativo na sociedade contemporânea, em que os indivíduos se tornam cada vez mais "vorazes por novidades e prazeres e pouco interessados em apegos fora de moda e compromissos duradouros" (2010, p. 93-4).

Figura 2 - Excitação em rosto

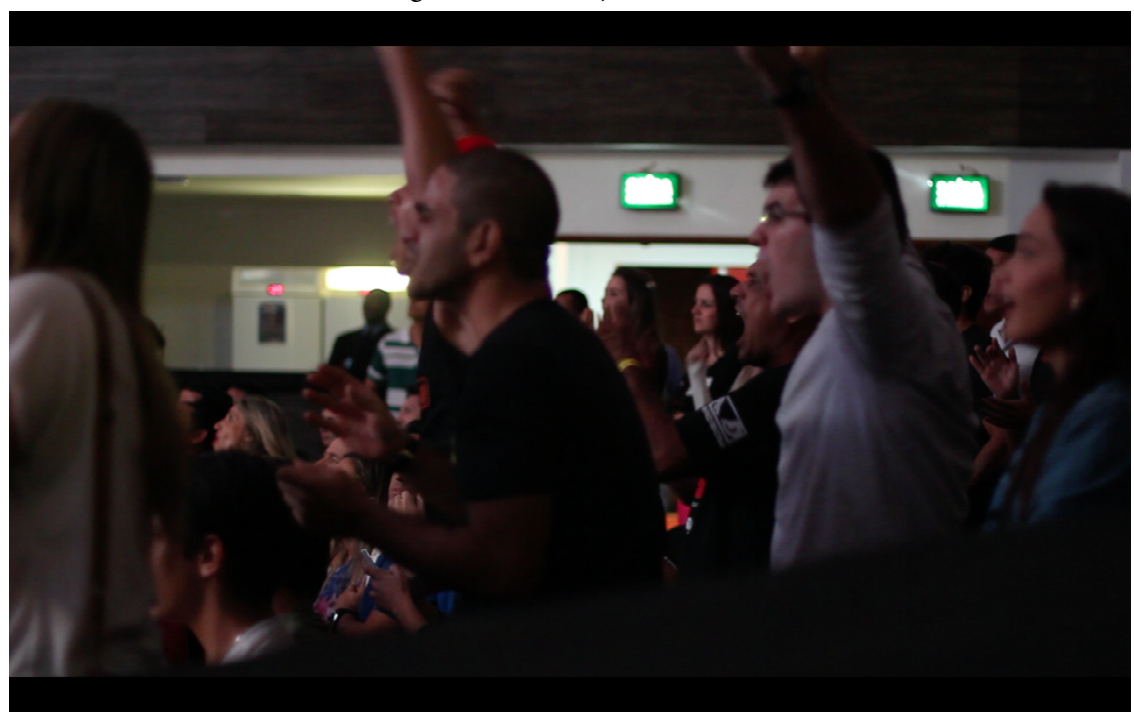

Fonte: Acervo da pesquisa, foto por Felipe Guimarães

Em nosso atual estágio não apenas dispomos de um prazer autorregulado pela introjeção de normas morais de caráter universalizante, como também nossas experiências sensoriais se misturam cada vez mais com o consumo de objetos que garantem nossa satisfação emocional. Jean Baudrillard (1970) chama de funmorality essa disposição contemporânea para nos divertirmos a todo custo e explorarmos intensamente todas as emoções. A insatisfação é o motor da vida social 
e a fun-morality é a insatisfação própria da sociedade do consumo ${ }^{11}$. Desse modo, argumentamos que o êxtase produzido nos espectadores do MMA não se dá única e exclusivamente pela imersão na experiência da luta, seja ela ao vivo ou transmitida por um aparelho de TV. Ele é resultante de um conjunto de experiências atreladas ao universo do consumo, tais como a fruição associativa da cultura dos bares, o prazer gustativo proporcionado pelo consumo de alimentos e bebidas alcoólicas e não alcoólicas, como também as expectativas das trocas erótico-afetivas que podem vir a ser concretizadas no referido espaço como também fora dele.

A problemática da produção do MMA abrange a diversão como motivação para o consumo. Tais motivações se transformam em predisposições de consumo que abrangem o que chamamos de estética do êxtase. A dimensão do bem-estar, tal qual explanamos em algumas passagens deste tópico, sugere uma lógica social do consumo pautada na relação do indivíduo com essa nova proposta de esporteentretenimento, relação que também é mediada por referenciais simbólicos que são utilizados na definição dos modelos idealizados de masculinidade.

\section{Consumir a luta: ritual e prática masculinizante}

Discutir o fenômeno da masculinidade torna-se questão imprescindível quando adentramos no universo do MMA, seja pelo fator "quantitativo", uma vez que grande parte dos adeptos do esporte (praticantes e espectadores) é composta por homens, seja pelo fator "qualitativo", pois nos deparamos com significações sociais que ao longo das mais distintas épocas vêm definindo percepções sobre o masculino. É importante esclarecer que ao utilizar a expressão "prática masculinizante" não estamos defendendo a ideia de que exista uma expressão masculina em essência, mas sim chamando atenção para aspectos referentes à diferenciação e desigualdade entre os gêneros no esporte em questão.

Masculinidade e feminilidade não são sobreponíveis, respectivamente, a homens e mulheres: são metáforas de poder e de capacidade de acção, como tal acessíveis a homens e mulheres. Se assim não fosse, não se poderia falar nem de várias masculinidades nem de transformações nas relações de género. O carácter móvel e contingente da relação entre masculinidade, homens e poder toma-se claro quando analisamos etnografias que prestam atenção ao diálogo e conflito entre masculinidades hegemónicas e subordinadas, ou que prestam atenção quer à variabilidade individual das identidades masculinas, quer às alterações destas num só indivíduo ao longo do ciclo de vida ou consoante diferentes situações de interacção (ALMEIDA, 1996, p. 161).

11 O sociólogo Jean Baudrillard cunhou o termo sociedade do consumo para explicitar um estágio diferenciado da sociedade capitalista onde já não se consome coisas, mas signos. Com o intuito de tornar a mercadoria atraente associa-se a ela significados diversos que dão estatuto diferenciado a mesma. Sob a ótica de Baudrillard, essas marcas simbólicas substituiriam a funcionalidade da mercadoria, tornando-se mercadoria-signo. 
$\mathrm{Na}$ citação acima, o antropólogo português Miguel Vale de Almeida, problematiza as definições de masculino e feminino como metáforas de poder e de capacidade de ação, sugerindo que ambas não pertencem por associação direta e de maneira exclusiva a homens e mulheres, ou seja, elas são negociadas a partir de diferentes contextos e situações.

No fenômeno aqui investigado, especialmente neste tópico, nossa atenção se volta para as relações entre homens e mulheres costuradas pelas tramas do MMA. Sem querer desconsiderar a agência feminina nesses espaços e eventuais subversões de hierarquias, foi possível constatar que muitas dessas relações reproduziam estruturas de poder que reforçavam estereótipos de gênero atrelados aos corpos, atribuindo aos mesmos distintos valores. Apesar das críticas ${ }^{12}$ dirigidas ao conceito de masculinidade hegemônica (CONNEL, 1995), entendemos que ele ainda pode ser útil para pensar a desigualdade entre os gêneros, pois, uma das suas principais utilizações foi em pesquisas no campo da Sociologia do Esporte, abordando a popularização dos chamados esportes de contato e confronto (onde o MMA se insere) bem como a problematização da violência e da homofobia em contexto esportivo (CONNEL; MESSERSCHMIDT, 2013).

É inegável que as mulheres também estão inseridas na condição de praticantes e espectadoras dessa prática esportiva, mesmo que ainda representem uma fatia muito pequena do chamado "público-alvo". Seja dentro dos bares, nas academias, ou mesmo no octógono, cada vez mais vem aumentando o número de mulheres imersas na rede de consumidores e consumidoras do MMA, e um elemento decisivo para essa expansão foi a visibilidade produzida com a entrada delas nas categorias competitivas profissionais ${ }^{13}$.

No entanto, apesar dessa aproximação feminina, não conseguimos perceber mudanças significativas no que diz respeito aos processos que envolvem a dinâmica simbólica das artes marciais mistas, uma vez que o complexo de significações desse novo esporte-entretenimento continua imerso em uma lógica binária hierarquizante que atribui valores distintos aos corpos dos homens e das mulheres.

Do próprio conflito da luta, passando pelo comportamento no bar, podemos vislumbrar uma rede de representações que evidenciam e favorecem a desigualdade de gênero. Tais práticas se valem de todo o aparato cultural e de características sociais de cada indivíduo que se reflete em comportamento de compra. Em nosso caso, dos comportamentos de compra que permeiam o MMA, a masculinidade construída socialmente reforça a ideia de êxtase que tal luta propicia. Bourdieu (1998), ao comentar sobre a diferenciação de gênero na sociedade Cabila, indica que:

12 Algumas dessas críticas referem-se à ausência de uma maior complexidade para pensar as hierarquias de gênero, pouca importância atribuída à agência feminina, bem como a ausência de intersseccionalidade entre os níveis global, local e regional para pensar os novos registros de masculinidade. Uma proposta de reformulação do conceito de masculinidade hegemônica pode ser vista em Connel e Messerschmidt (2013).

13 A participação de atletas profissionais do sexo feminino no UFC teve início no ano de 2013, para ser mais específico, no dia 23 de fevereiro, quando houve a primeira luta feminina da história desse torneio. 
[...] a somatização de diferenças de gênero socialmente instituídas age pela organização simbólica e prática dos usos diferenciados do corpo (mobilidade e postura) e de ritos que efetuam a virilização dos meninos e a feminização das meninas (BOURDIEU, 1998, p. 21).

De maneira semelhante aos cabila, as sociedades ditas ocidentalizadas também possuem uma organização simbólica e ritos que demarcam a diferenciação e a desigualdade dos gêneros mediante a "virilização das condutas masculinas" e a "feminilização das condutas das mulheres". Nesse esquema de reificação dos sistemas simbólicos, o pêndulo do poder se move em direção aos homens, reforçando estereótipos e naturalizando condutas.

O debate atual acerca da masculinidade nos apresenta justamente esse movimento de significativa relevância do habitus como construtor das práticas sociais. A supervalorização da figura masculina, que envolve também o consumo das lutas de artes marciais mistas, é potencializada, inclusive, pelas representações simbólicas que fazem parte da proposta de oferta do MMA.

Uma vez que tal oferta é consumida, cria-se o fortalecimento de uma "configuração masculinizante" 14 específica desse novo tipo de esporte-entretenimento como negócio e o bar é um desses ambientes que potencializam essa diferenciação como item do escopo principal do processo de consumo das artes marciais mistas.

O corpo é uma peça fundamental nesse sistema simbólico de propagação do êxtase e da construção social da masculinidade. Para as artes marciais mistas, o corpo tem um papel extremamente relevante no processo de representação simbólica tanto do ponto de vista do esporte quanto do ponto de vista do entretenimento e, consequentemente, do negócio.

Na lógica simbólica de promoção do MMA há aspectos que reforçam a construção do corpo como componente específico de um sistema de valor pautado pela "beleza" física, pelo sensual e pelo erotismo. A mulher na posição de "Octogon Girl” ou "Ringue Girl” surge para intensificar a propagação do êxtase masculino. Ela não fala nem interfere na luta, apenas desfila entre um intervalo e outro com a placa que informa o número do round que está por vir. Desse modo, as mulheres são percebidas como produtos de um espetáculo a ser consumido majoritariamente por homens, o que demarca a desigualdade dos gêneros no que diz respeito às diferentes posições ocupadas por homens e mulheres no campo do MMA.

No evento Coliseu Extreme Fight VII, realizado em Maceió, Alagoas, as "Ringue Girls" foram anunciadas como atrações ao lado dos lutadores. Na ocasião, estavam presentes a "Miss Bumbum São Paulo", a "Miss Bumbum Rio de Janeiro" e a modelo Aryane Steinkopf, conhecida popularmente como a "mais bela ringue girl

14 A ideia de "configuração masculinizante" sugere um esquema de percepções e ações elaborado a partir de uma visão de mundo assentada sob uma perspectiva assimétrica dos gêneros. Não se trata de atribuir a esses sentidos uma essência masculina, e sim indicar, que eles são devedores de uma lógica que associa corpo, gênero e performance. 
do Brasil". A cada intervalo da luta, uma delas subia ao octógono para informar aos que estavam ali presentes o número do próximo round. O público, por sua vez, especialmente os homens, prestava rigorosa atenção e vibravam com os movimentos daquelas que possuíam pouca roupa.

Figura 3 - O corpo feminino no MMA: as "Ringue Girls"

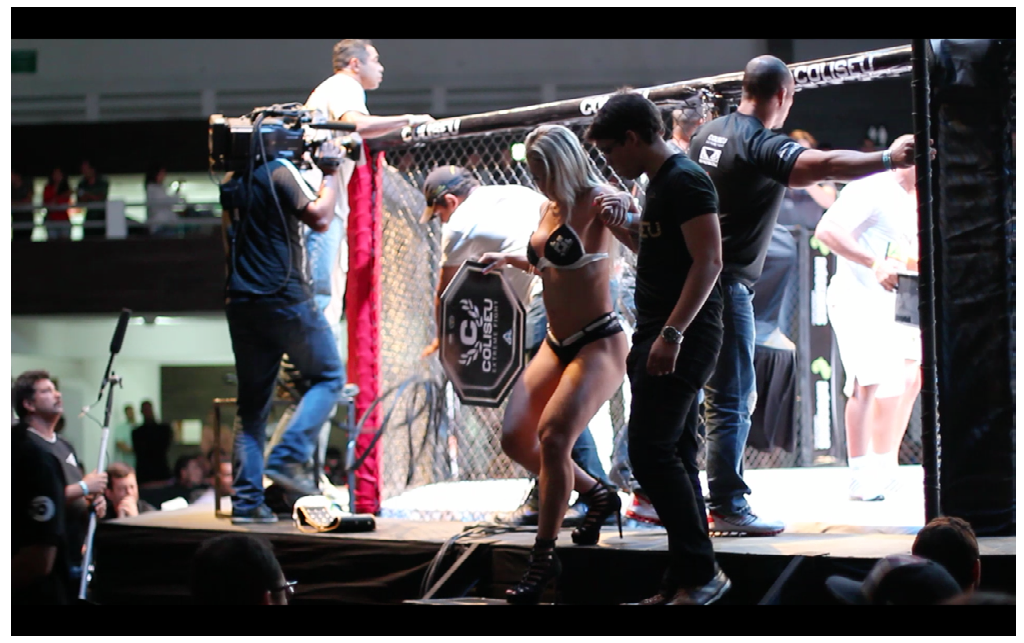

Fonte: Acervo pessoal, por Felipe Guimarães.

O papel dessas mulheres no contexto do UFC favorece a lógica simbólica que estamos chamando de propagação do êxtase, que, nesse caso específico, possui como referência o público masculino, pois, este é o grupo que incorpora de maneira mais intensa o "sentido do jogo" (BOURDIEU, 1996). Essa intensidade a que estamos nos referindo compreende as demonstrações exageradas de euforia diante de um golpe bem aplicado durante uma luta ou diante da exibição de um corpo feminino com pouca roupa. $\mathrm{O}$ que não significa afirmar que mulheres também não podem dar vazão a essas emoções, porém, durante a pesquisa de campo, percebemos demonstrações "mais contidas" ou "menos entusiasmadas" por parte do público feminino, mesmo em situações em que a luta era entre mulheres.

Mais uma vez, esclarecemos que essa diferenciação não possui relação com supostos atributos ou disposições que seriam inerentes à condição masculina e feminina. Ela compreende processos sociais e culturais mais abrangentes que são incorporados por homens e mulheres, influenciando de maneira decisiva nas ações desses agentes. Concordando com a argumentação de Butler (2016), entendemos que não existem performances que sejam essencialmente masculinas ou femininas, e sim corpos sendo agenciados por significações que estabelecem princípios normativos para essas expressividades, logo, enquanto pesquisadores, cabe a nós buscarmos pistas para a compreensão dos processos responsáveis pela produção dessas estruturas de sentido. 


\section{Considerações finais}

Conforme apresentamos ao longo do artigo, o MMA é um fenômeno complexo que articula elementos do plano macrossocial (estrutura econômica, fluxos midiáticos) e microssocial (emoções, desejos) cuja síntese se expressa corporalmente. Apoiados em argumentos sociológicos e antropológicos, entendemos que ao longo das diferentes épocas, o corpo foi sendo moldado a partir das mudanças estruturais e dos seus registros simbólicos. O processo de individualização, a latente desvinculação das tradições comunitárias e populares em detrimento do discurso médico-científico, a expansão do pensamento reflexivo e o distanciamento da natureza impactaram diretamente em nossa atual concepção de corpo, e mesmo que estejamos baseados em dados extraídos localmente, não podemos perder de vista esses aspectos mais gerais.

A partir dessa articulação entre aspectos globais e locais, propomos algumas reflexões sobre os sentidos elaborados pelos praticantes e espectadores do MMA, destacando aspectos relacionados às práticas de consumo, desigualdade de gênero no esporte e a produção do êxtase. A dimensão corporal possui importância significativa para a construção do imaginário e a perpetuação dos valores de consumo propostos que compreendem justamente as construções simbólicas que são elaboradas para repercutir o tal novo esporte-entretenimento na sociedade. $\mathrm{O}$ corpo torna-se, então, objeto de representações que intensificam o desejo do público-alvo.

As etnografias realizadas nas academias, nos bares e em um grande evento esportivo permitiram que tivéssemos uma visão mais detalhada do fenômeno investigado, bem como das percepções dos agentes que estão dentro (praticantes) e fora (espectadores) do octógono. Apesar de termos feito essa classificação entre os distintos públicos, entendemos que ambos são consumidores do esporte e reproduzem a lógica simbólica que o fundamenta.

\section{Referências}

ALMEIDA, Miguel Vale de. Gênero, masculinidade e poder: revendo um caso do Sul de Portugal. Anuário Antropológico, Rio de Janeiro, 95, p. 161-190, 1996.

BAUDRILLARD, Jean. La société de consommation. Paris: Gallimard, 1970.

BOURDIEU, P. Esquisse d'une théorie de la pratique. Genève: Lib. Droz, 1972.

. Razões Práticas: sobre a teoria da ação. Campinas, SP: Papirus, 1996.

. Conferência do prêmio Goffman: a dominação masculina revisitada. In: LINS, Daniel (Org.). A

dominação masculina revisitada. Campinas: Papirus, 1998, p. 11-27.

BUTLER, Judith. Problemas de gênero: feminismo e subversão da identidade. Rio de Janeiro: Civilização Brasileira, 2016.

CONNEL, Raewyn. Masculinities. Cambridge, UK: Polity Press, 1995. ; MESSERSCHMIDT, J.W. Masculinidade hegemônica: repensando o conceito. Revista Estudos feministas, Florianópolis, n. 21, v. 1, p. 241-282, jan./abr./2013. 
ELIAS, Norbert. O processo civilizador: uma história dos costumes. Rio de Janeiro: Jorge Zahar Ed., 1990. ELIAS, Norbert; DUNNING, Eric. A busca da excitação. Lisboa: Difel, 1992.

. A Sociedade dos indivíduos. Rio de Janeiro: Jorge Zahar Ed., 1994.

FOUCAULT, Michel. História da sexualidade: a vontade de saber. Rio de Janeiro: Graal, 1988, vol 1.

. Vigiar e Punir: o nascimento da prisão. Petrópolis, RJ: Vozes, 2009.

GIDDENS, Anthony. A constituição da sociedade. São Paulo: Martins Fontes, 1984

. Modernidade e identidade. Rio de Janeiro: Jorge Zahar Ed., 2002.

HERTZ, Robert. A preeminência da mão direita: um estudo sobre a polaridade religiosa. Religião e Sociedade. Rio de Janeiro, Tempo e Presença, n.6, p. 99-128, 1980.

GUIMARÃES, F.C. Práticas sociais do consumo pelo êxtase: artes marciais mistas, masculinidade e o novo esporte-entretenimento. 2014. Dissertação (Mestrado em Sociologia) Instituto de Ciências Sociais, Universidade Federal de Alagoas, Maceió, 2014.

LANCEPRESS. Os 20 anos do UFC: a trajetória do maior evento de MMA do mundo. Rio de Janeiro, 2013. Disponível em: <http://www.lancenet.com.br/minuto/UFC-nascimento-evento-MMAmundo_0_1028297164.html>. Acesso em: 20 nov. 2013.

LE BRETON, David. Sociologia do corpo. Petrópolis, RJ: Vozes, 2011.

MAUSS, Marcel. As técnicas do corpo. In: . Sociologia e antropologia. São Paulo: Cosac \& Naify, 2003, p. 399-422.

ORTEGA, Francisco; ZORZANELLI, Rafaela. A saúde como salvação: contexto cultural de ascensão do corpo como valor na contemporaneidade. Rio de Janeiro: Civilização Brasileira, 2010.

ORTNER, Sherry B. Theory in anthropology since the sixties. Comparative Studies in Society and History, n. 26, vol.1, 126-166, 1984.

Poder e projetos: reflexões sobre a agência. In GROSSI, M. P.; ECKERT, C.; FRY P. H.(Orgs.).

Conferências e diálogos: saberes e práticas antropológicas. Goiânia: Nova Letra, 2006, p. 45-80.

SAHLINS, Marshall. Ilhas de história. Rio de Janeiro: Zahar Editor, 1987.

WACQUANT, Loïc. Os três corpos do lutador profissional. In: LINS, Daniel (Org.). A dominação masculina revisitada. Campinas: Papirus, 1998, p. 73-96.

Corpo e alma: notas etnográficas de um aprendiz de boxe. Rio de Janeiro: Relume Dumará, 2002.

Recebido em 08/10/2017

Aceito em 14/02/2018 